\title{
Birthweight and the risk of childhood-onset type 1 diabetes: a meta-analysis of observational studies using individual patient data
}

\author{
C. R. Cardwell • L. C. Stene • G. Joner • E. A. Davis • O. Cinek • J. Rosenbauer • \\ J. Ludvigsson • C. Castell • J. Svensson • M. J. Goldacre • T. Waldhoer • J. Polanska • \\ S. G. A. Gimeno $~$ L.-M. Chuang • R. C. Parslow • E. J. K. Wadsworth • A. Chetwynd • \\ P. Pozzilli • G. Brigis • B. Urbonaitė • S. Šipetić • E. Schober • C. Ionescu-Tirgoviste • \\ C. E. de Beaufort • D. Stoyanov $\cdot$ K. Buschard • C. C. Patterson
}

Received: 11 September 2009 / Accepted: 10 December 2009/Published online: 10 January 2010

(C) Springer-Verlag 2010

\begin{abstract}
Aims/hypothesis We investigated whether children who are heavier at birth have an increased risk of type 1 diabetes. Methods Relevant studies published before February 2009 were identified from literature searches using MEDLINE, Web of Science and EMBASE. Authors of all studies
\end{abstract}

Electronic supplementary material The online version of this article (doi:10.1007/s00125-009-1648-5) contains supplementary material, which is available to authorised users.

C. R. Cardwell $(\varangle) \cdot$ C. C. Patterson

Centre for Public Health, School of Medicine,

Dentistry and Biomedical Sciences, Queen's University Belfast,

Grosvenor Road,

Belfast BT12 6BJ, UK

e-mail: c.cardwell@qub.ac.uk

L. C. Stene

Division of Epidemiology, Norwegian Institute of Public Health,

Oslo, Norway

L. C. Stene $\cdot$ G. Joner

Oslo Diabetes Research Centre, Oslo University Hospital,

Oslo, Norway

G. Joner

Faculty of Medicine, University of Oslo,

Oslo, Norway

E. A. Davis

Telethon Institute for Child Health Research,

Centre for Child Health Research,

The University of Western Australia,

Perth, WA, Australia

O. Cinek

The 2nd Medical School, Charles University,

Prague, Czech Republic containing relevant data were contacted and asked to provide individual patient data or conduct pre-specified analyses. Risk estimates of type 1 diabetes by category of birthweight were calculated for each study, before and after adjustment for potential confounders. Meta-analysis techniques were then used to derive combined ORs and investigate heterogeneity between studies.

Results Data were available for 29 predominantly European studies (five cohort, 24 case-control studies), including

\section{J. Rosenbauer}

Institute of Biometrics and Epidemiology,

German Diabetes Centre, Leibniz Institute at Duesseldorf University,

Duesseldorf, Germany

\section{J. Ludvigsson}

Department of Paediatrics and Diabetes Research Centre,

Linkoping University,

Linkoping, Sweden

C. Castell

Department of Health, Advisory Committee on Diabetes in Catalonia, Barcelona, Spain

J. Svensson

Pediatric Department, Glostrup University Hospital,

Glostrup, Denmark

M. J. Goldacre

Department of Public Health, Oxford University,

Oxford, UK

\section{T. Waldhoer}

Department of Epidemiology, Medical University of Vienna,

Vienna, Austria 
12,807 cases of type 1 diabetes. Overall, studies consistently demonstrated that children with birthweight from 3.5 to $4 \mathrm{~kg}$ had an increased risk of diabetes of $6 \%$ (OR 1.06 [95\% CI 1.01-1.11]; $p=0.02$ ) and children with birthweight over $4 \mathrm{~kg}$ had an increased risk of $10 \%$ (OR 1.10 [95\% CI 1.04-1.19]; $p=0.003$ ), compared with children weighing 3.0 to $3.5 \mathrm{~kg}$ at birth. This corresponded to a linear increase in diabetes risk of $3 \%$ per $500 \mathrm{~g}$ increase in birthweight (OR 1.03 [95\% CI 1.00-1.06]; $p=0.03$ ). Adjustments for potential confounders such as gestational age, maternal age, birth order, Caesarean section, breastfeeding and maternal diabetes had little effect on these findings.

Conclusions/interpretation Children who are heavier at birth have a significant and consistent, but relatively small increase in risk of type 1 diabetes.

Keywords Birthweight $\cdot$ Epidemiology $\cdot$ Meta-analysis . Risk factors · Type 1 diabetes mellitus

\section{Introduction}

Recent global estimates suggest that approximately 70,000 children per year are diagnosed with type 1 diabetes [1]. Worryingly, this incidence rate is almost universally

\section{J. Polanska}

Faculty of Automatic Control, Electronics and Computer Science,

Silesian University of Technology,

Gliwice, Poland

S. G. A. Gimeno

Preventive Medicine Department, Federal University of São Paulo,

São Paulo, Brazil

\section{L.-M. Chuang}

Department of Internal Medicine,

National Taiwan University Hospital,

Taipei, Taiwan

R. C. Parslow

Paediatric Epidemiology Group, University of Leeds,

Leeds, UK

E. J. K. Wadsworth

Centre for Occupational and Health Psychology, Cardiff University,

Cardiff, UK

\section{A. Chetwynd}

Mathematics and Statistics Department, Lancaster University,

Lancaster, UK

P. Pozzilli

University Campus Bio-Medico,

Rome, Italy

\section{G. Brigis}

Department of Public Health and Epidemiology,

Riga Stradins University,

Riga, Latvia increasing by around $4 \%$ annually [2, 3]. Although the aetiology of the disease is largely unknown, these increases within genetically stable populations suggest the role of environmental influences. It has been proposed that events occurring early in life could be of particular importance [4].

Birthweight is associated with various perinatal factors such as maternal age, gestational age, maternal weight and nutritional status, and maternal diseases [5]. High birthweight has been associated with an increased risk of childhood cancers such as leukaemia [6] and brain tumours [7].

Numerous studies have investigated the role of birthweight in childhood-onset type 1 diabetes. The findings of this research seem inconsistent, as some studies have concluded that high birthweight is associated with increased diabetes risk [8] or reduced diabetes risk [9], while others have shown no association with type 1 diabetes risk [10]. Interpretation of these findings is made more difficult because studies have reported associations using many different categorisations of birthweight [8, 11-14], with some $[15,16]$ only reporting findings for the extremes of birthweight and others [17-21] not reporting their birthweight results in any detail, concentrating instead on other findings. This could lead to reporting bias if the decision to report birthweight findings was influenced by whether or not results were interesting or 'statistically significant'.

B. Urbonaitè

Institute of Endocrinology, Kaunas University of Medicine,

Kaunas, Lithuania

\section{S. Šipetić}

Institute of Epidemiology, School of Medicine, Belgrade University, Belgrade, Serbia

E. Schober

Department of Paediatrics, Medical University of Vienna,

Vienna, Austria

C. Ionescu-Tirgoviste

Nutrition and Metabolic Diseases Clinic,

N. Paulescu Institute of Diabetes,

Bucharest, Romania

\section{E. de Beaufort}

Clinique Pédiatrique,

Luxembourg, Luxembourg

D. Stoyanov

Children's Diabetic Centre,

Sofia, Bulgaria

K. Buschard

Bartholin Instituttet, Rigshospitalet,

Copenhagen, Denmark 
Finally, many studies had limited power to detect associations with birthweight due to inadequate sample size.

We performed the first meta-analysis using individual patient data to: (1) assess the evidence of an association between birthweight and type 1 diabetes; (2) explore the shape of any association; and (3) adjust the observed association for potential confounders (such as gestational age, maternal age and maternal diabetes).

\section{Methods}

Literature search The main literature search was conducted using MEDLINE, through Ovid Online (www.ovid.com). The search strategy used the following terms: ('Birth weight' or birth weight or birthweight) and ('Diabetes Mellitus, Type 1' or [diabetes and Type 1] or IDDM), with the terms in inverted commas used as MEDLINE subject heading key words. Similar searches were conducted on Web of Science (http://apps.isiknowledge.com) and EMBASE (www.embase.com). Finally, to identify studies that investigated birthweight along with other risk factors, a more general search was conducted on MEDLINE using the terms: ('Diabetes Mellitus, Type 1' and ['Case-control Studies' or 'Cohort Studies']). The searches were limited to studies on humans published before July 2009. Abstracts were screened independently by two investigators (C. R. Cardwell, C. C. Patterson) to establish whether the studies were likely to provide relevant data based on the following inclusion criteria: (1) the studies identified a group with type 1 diabetes and a group without type 1 diabetes; and (2) they recorded birthweight in these two groups. Studies were excluded if they contained fewer than 100 cases or if they were family-based (because it is possible that the association between birthweight and diabetes is different in individuals with a higher genetic susceptibility). Citations generated from the more general MEDLINE search were initially screened to remove obviously irrelevant articles. Finally, the reference lists of all pertinent articles were hand-searched and corresponding authors of articles included in the review were asked if they were aware of any additional studies.

The corresponding author of each study included was requested to provide data on the association between birthweight and type 1 diabetes in the following categories: $<2.5,2.5-3.0,3.0-3.5,3.5-4.0, \geq 4 \mathrm{~kg}$. It was necessary to contact authors because it was generally not possible to extract such data from the published reports, as they reported birthweight using different categorisations or (in some cases) did not report their birthweight data at all. It was also necessary to contact authors to facilitate consistent adjustment of the association with birthweight for the following potential confounders: gestational age, maternal age, birth order, breastfeeding, Caesarean section and maternal diabetes. Authors were requested to provide raw data or to provide adjusted estimates of the association between birthweight and type 1 diabetes after conducting specified additional analyses.

Details of studies included (country, design, year of publication and response rates), participants with type 1 diabetes (source, age at onset) and control participants (source) were extracted by one reviewer (C. R. Cardwell) and confirmed by the corresponding authors of the respective studies.

Statistical analysis Odds ratios and SEs were calculated for the association between diabetes and each category of birthweight for each study. Similarly, to investigate the trend across categories of birthweight, an OR (and SE) was calculated per increase in category (corresponding to approximately $500 \mathrm{~g}$ ) using regression models appropriate to the design of the study. Unconditional and conditional logistic regression analyses were used to calculate ORs and SEs for the unmatched and matched case-control studies, respectively. In cohort studies with varying duration of participant follow-up, rate ratios and their SEs were used instead of ORs, which were not directly calculable. As type 1 diabetes is a rare disease, these measures should be approximately equal [22]. Poisson regression was used to adjust these rate ratios for differences in the year of birth between those developing diabetes and those not, a consequence of this study design, by adding a year of birth term to the regression model in addition to birthweight. Tests for heterogeneity between studies were conducted and random-effects models used to calculate pooled ORs [23]. Random-effects models were deemed more appropriate than fixed-effects models because it was anticipated that between-study heterogeneity would exist, due to the observational nature of studies. The $I^{2}$ statistic was calculated to quantify the degree of such heterogeneity [24]. This statistic measures the percentage of total variation across studies due to heterogeneity. Publication/ selection bias was investigated by checking for asymmetry in funnel plots of the study ORs against the standard error of the logarithm of the ORs [25].

A two-stage technique was used to calculate pooled estimates of the association between birthweight and diabetes after adjustment for potential confounders [26]. First, adjusted estimates and SEs were calculated within each study using regression models appropriate to the study design (logistic regression for case-control studies, conditional logistic regression for matched case-control studies and Poisson regression for cohort studies); regression models included diabetes as the outcome variable and birthweight and the potential confounder(s) of interest as explanatory variable(s). As explained previously, Poisson regression models additionally included terms to adjust for differences in year of birth between cases and controls in the cohort 
studies with varying participant follow-up. Meta-analysis techniques were then applied to these adjusted estimates.

Sub-group analyses were conducted subdividing studies by type (case-control and cohort) and including only studies with a low risk of bias (excluding case-control studies in which controls were not population-based or not randomly selected controls, and excluding any study with a response rate of less than $80 \%$ in the case group or control group). A separate analysis was conducted by age at onset of diabetes.

All statistical analyses were performed using STATA 9.0 (Stata, College Station, TX, USA).

\section{Results}

Search results The searches identified 81 relevant articles. Of these, 35 were excluded because they contained duplicate or overlapping information; only the most comprehensive article was retained in the review. Ten articles were excluded because they contained information on fewer than 100 cases, six articles were excluded because they had family-based designs and a further article was excluded (after contact with the author) because birthweight was not recorded in sufficient detail [27]. A full list of the papers identified by the searches is available from the authors.

The remaining 29 articles [8-13, 15-19, 21, 28-44] contained information from 34 independent studies, as information from five centres was taken from one article [15] and information from two centres was taken from another [19]. An investigator from each of the 34 studies was invited to provide raw data (or estimates from pre-specified analyses), but one author [40] could not be contacted. Individual patient data or pre-specified estimates were obtained from 29 studies (in one study [28], data were extracted directly from the published report). Characteristics of these predominantly European studies are shown in Table 1.

Birthweight and type 1 diabetes The association between birthweight and type 1 diabetes from these 29 included studies (with a total of 12,087 cases of type 1 diabetes) is shown in Fig. 1. Overall, children with higher birthweights had small increases in their risk of type 1 diabetes. Specifically, children weighing 3.5 to $4.0 \mathrm{~kg}$ at birth had on average a $6 \%$ increase and children born heavier than $4.0 \mathrm{~kg}$ had on average a $10 \%$ increase in their risk of diabetes ( $p=0.02$ and $p=0.003$, respectively); there was little heterogeneity in these increases between studies $\left(I^{2}=0, p=0.70\right.$ for heterogeneity and $I^{2}=0, p=0.94$ for heterogeneity, respectively). No difference in the risk of diabetes was found in children weighing 2.5 to $3.0 \mathrm{~kg}$ at birth (combined OR 1.01, $p=0.82$ ) compared with children of 3.0 to $3.5 \mathrm{~kg}$ birthweight. There was also no difference in the risk of diabetes in children born lighter than $2.5 \mathrm{~kg}$ (combined OR 0.98, $p=0.75$ ); however, we did find evidence of marked heterogeneity between studies for this association ( $p=0.01$ for heterogeneity, $I^{2}=42$ ). Figure 1 shows that this heterogeneity was partly due to the study designs. Cohort studies consistently ( $p=0.64$ for heterogeneity, $I^{2}=0$ ) demonstrated a reduced risk of diabetes in children born lighter than $2.5 \mathrm{~kg}$ (combined OR $0.79, p=0.002)$, while case-control studies were less consistent $\left(p=0.03\right.$ for heterogeneity, $\left.I^{2}=38\right)$ and found no evidence of reduced risk of diabetes in children born lighter than $2.5 \mathrm{~kg}$ (combined OR 1.07, $p=0.45$ ). Finally, funnel plots of the association between birthweight in categories and risk of type 1 diabetes (Electronic supplementary material [ESM] Fig. 1) roughly conformed to the expected funnel shape, providing little evidence of asymmetry and therefore little evidence of publication bias. Further analysis comparing children weighing over $4 \mathrm{~kg}$ at birth with children weighing under $4 \mathrm{~kg}$ revealed a combined OR of $1.09(95 \%$ CI 1.02-1.15; $p=0.006$ ); for children weighing under $2.5 \mathrm{~kg}$ at birth vs those weighing over $2.5 \mathrm{~kg}$, the combined OR was 0.93 (95\% CI 0.80-1.08; $p=0.32$ ).

A linear trend in the risk of type 1 diabetes per category increase in birthweight (corresponding to approximately $500 \mathrm{~g}$ ) was also investigated (Table 2). Although we found evidence $(p=0.03)$ of a linear increase in the risk of diabetes by on average $3 \%$ per $500 \mathrm{~g}$, this was subject to heterogeneity $\left(I^{2}=35 \%, p=0.03\right)$; moreover, Fig. 1 revealed a number of studies $[9,18,31,43]$ which did not seem to conform to a linear trend.

Adjustments for potential confounders Table 2 shows the overall results for birthweight before and after adjustments for potential confounders. The results after adjustment for maternal age, gestational age and birth order are largely consistent with the unadjusted results, except that the overall OR in the under $2.5 \mathrm{~kg}$ category is slightly reduced (adjusted OR 0.87 ); consequently the OR per $500 \mathrm{~g}$ increase is slightly increased (adjusted OR 1.05). The fully adjusted results, which were additionally adjusted for breastfeeding, Caesarean section and maternal diabetes (information on available confounders, see Table 1), are also shown and differed only slightly (Table 2). Repeating the analysis after removal of children born to mothers with diabetes in the 20 studies with available data had little impact on the association between birthweight and type 1 diabetes (data not shown).

Analysis by study quality Table 2 also contains an analysis in 12 studies with a low risk of bias (excluding case-control studies with non-population based or not randomly selected controls, and excluding any study with a response rate of less than $80 \%$ in the case or control group, as shown in Table 1). In these 12 studies, a slightly more marked association between birthweight and type 1 diabetes was seen. Thus compared with the 3.0 to $3.5 \mathrm{~kg}$ birthweight 


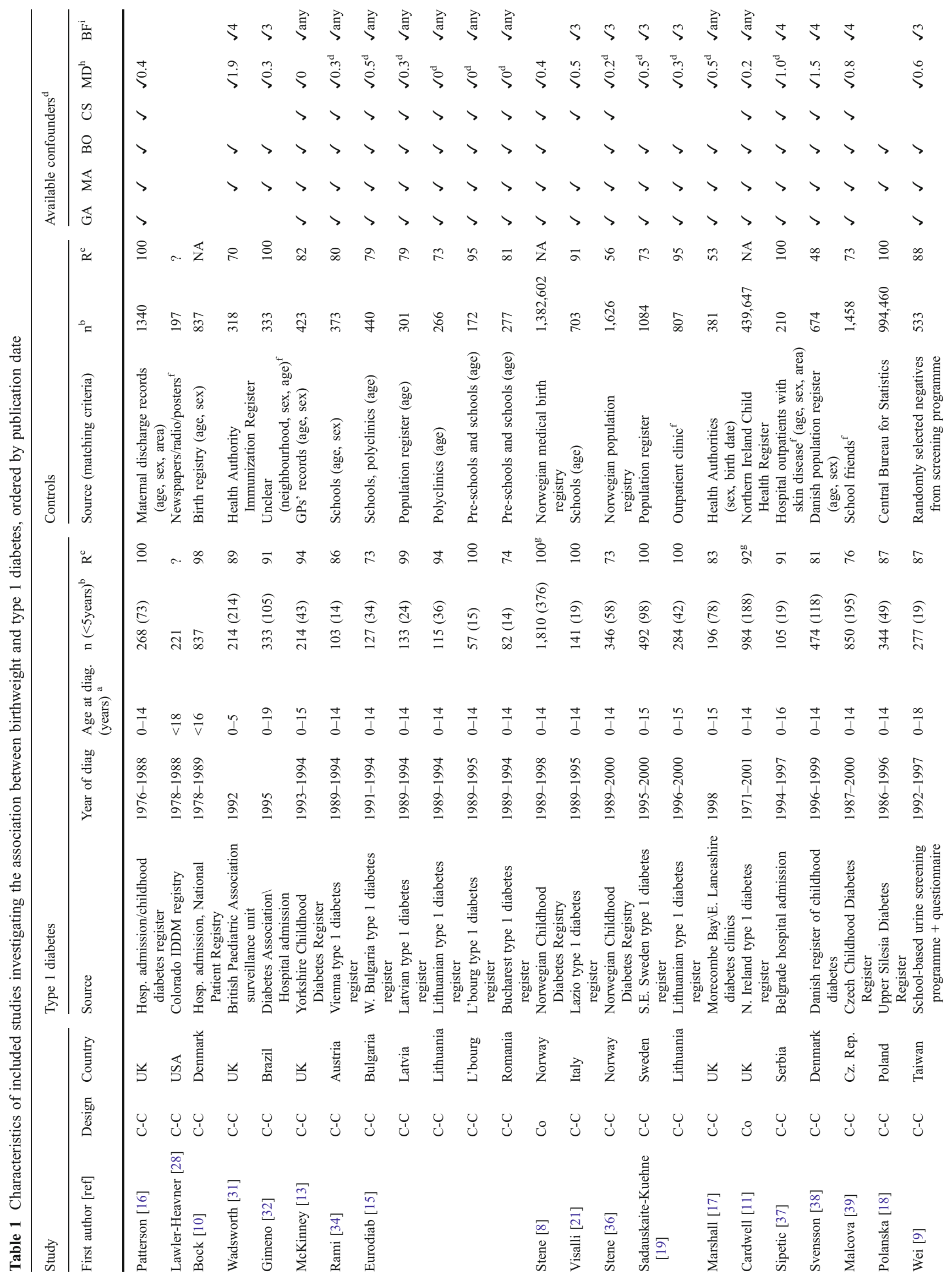




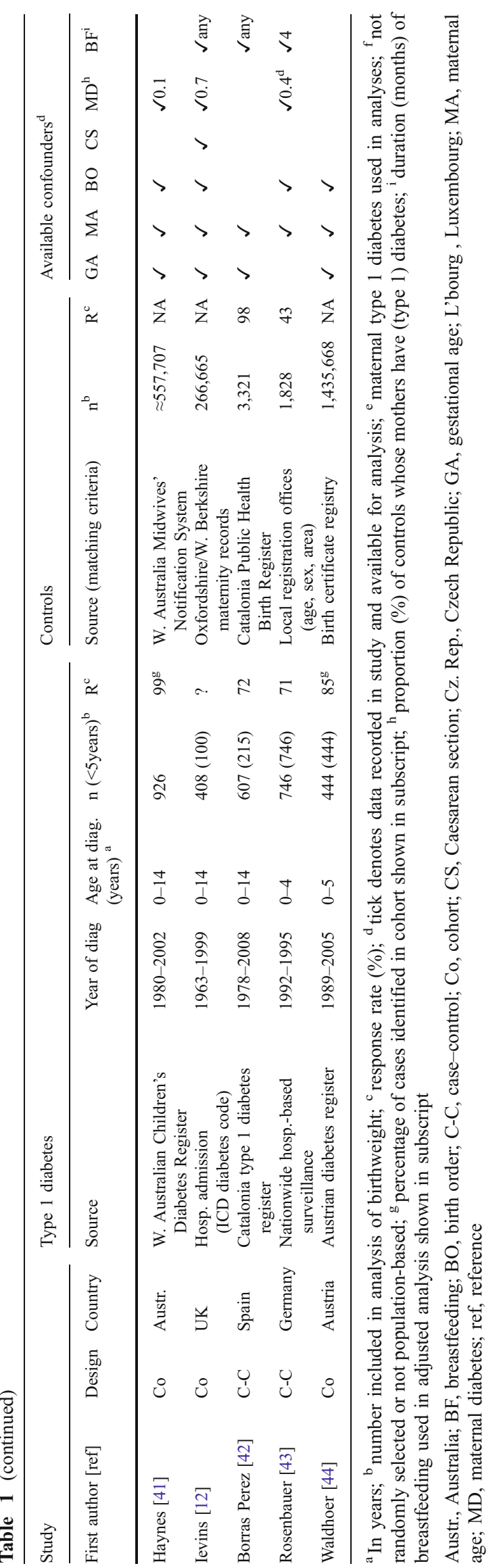




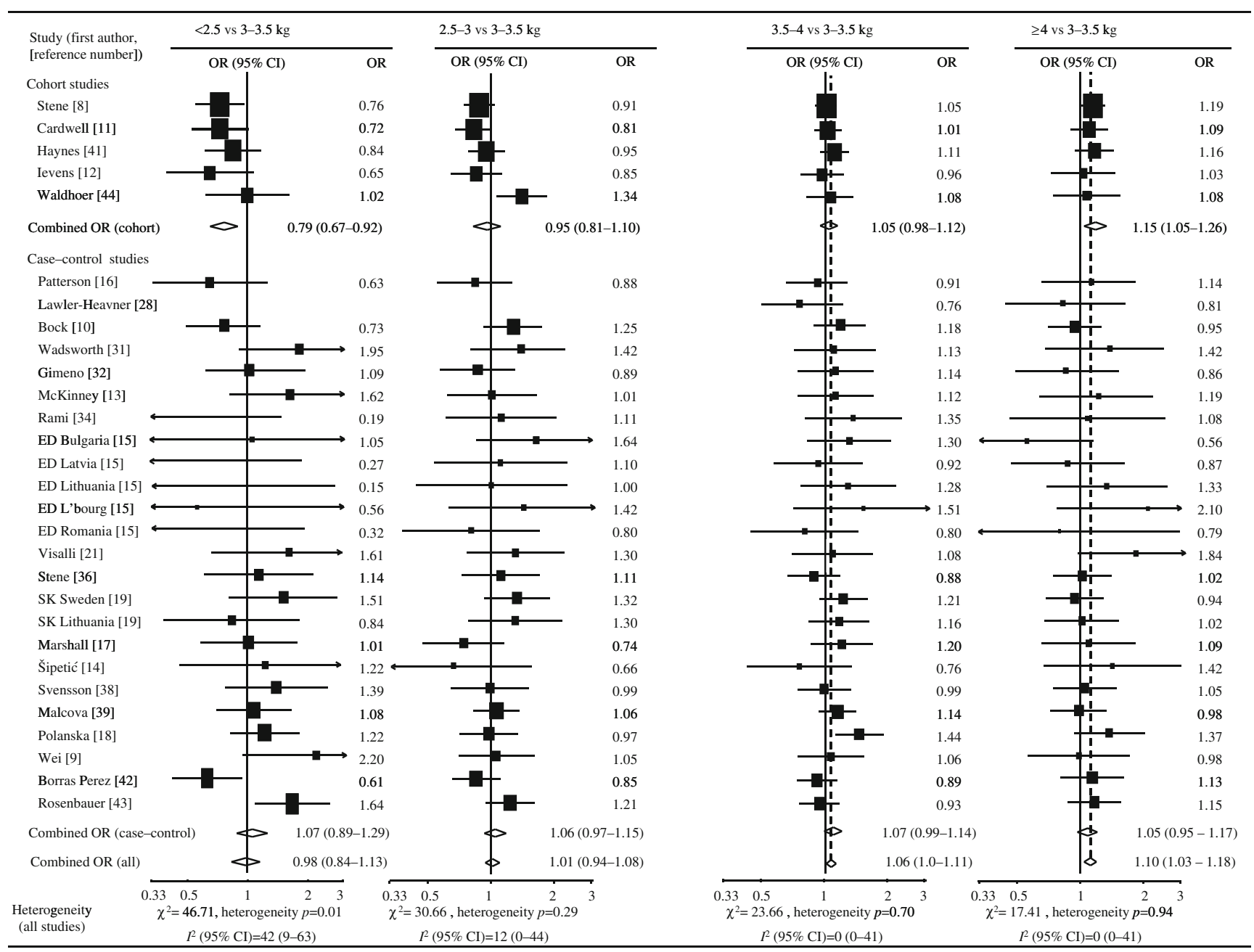

Fig. 1 Meta-analyses of the unadjusted association between birthweight in categories (compared with reference category 3-3.5 kg) and type 1 diabetes including 12,087 cases) using the random effects model, studies ordered by publication date. L'bourg, Luxembourg

category, the increase in diabetes risk in children of 3.5 to $4.0 \mathrm{~kg}$ birthweight was $9 \%$, while that in children born heavier than $4.0 \mathrm{~kg}$ was $16 \%$. These studies also showed a more marked increase in diabetes risk per $500 \mathrm{~g}$ increase in birthweight, namely $7 \%$, with considerably less heterogeneity in their estimates $\left(I^{2}=12 \%, p=0.32\right)$.

Analysis by age at onset There was little evidence of a difference in the association between birthweight and type 1 diabetes in early-onset (age under 5 years) cases and later onset (age over 5 years) cases in the 23 studies in which these data were available. For instance, per $500 \mathrm{~g}$ increase in birthweight, there was a 4\% (OR 1.04 [95\% CI 0.99 $1.09]$ ) increase in early-onset and a 4\% (OR 1.04 [95\% CI 1.01-1.08]) increase in later onset disease.

Other studies In five of the studies identified by our searches $[29,30,33,35,40]$ the required data could not be obtained from authors (or extracted from the published reports). In a
Swedish study [30] (with 4,584 cases of type 1 diabetes) we were able to estimate results from a figure, but only using a different reference category (of 3.0 to $4.0 \mathrm{~kg}$ ). Recalculating estimates using this reference category in 28 of the studies included (and for which data were available) generated an increased risk of diabetes in children born heavier than $4.0 \mathrm{~kg}$ of $8 \%$ (combined OR 1.08 [95\% CI 1.02-1.15]; $p=0.01$ ) compared with children weighing 3.0 to $4.0 \mathrm{~kg}$ at birth. After adding this Swedish study, this increase in risk was little altered (combined OR 1.07 [95\% CI 1.02-1.12]; $p=0.01$ ).

A study from Finland [35] (662 cases) reported an increase in mean birthweight in cases compared with controls in males (3.7 vs $3.6 \mathrm{~kg}$, respectively; $p=0.04$ ) and in females (3.6 vs $3.5 \mathrm{~kg}$, respectively; $p=0.49$ ). A study from Denmark (with 839 cases) reported no significant difference in birthweight between cases and controls. Finally, two other studies, one from Hungary [29] and one from USA [40], reported little evidence of a difference, but contained relatively few cases (163 and 103, respectively). 
Table 2 Meta-analyses of 29 studies investigating the association between birthweight and type 1 diabetes (including 12,087 cases) before and after adjustments for recorded confounders and in studies with low risk of bias

\begin{tabular}{|c|c|c|c|c|c|}
\hline \multirow[t]{2}{*}{ Analysis per birthweight categories $(\mathrm{kg})$} & \multirow[t]{2}{*}{ Cases $(n)$} & \multirow[t]{2}{*}{ Combined OR (95\% CI) } & \multirow[t]{2}{*}{$p$ value } & \multicolumn{2}{|l|}{ Heterogeneity } \\
\hline & & & & $\chi^{2}(p)$ & $I^{2}$ \\
\hline \multicolumn{6}{|l|}{ Unadjusted $^{\mathrm{a}}$} \\
\hline$<2.5$ & 554 & $0.98(0.84-1.13)$ & 0.75 & $46.71(0.01)$ & 42 \\
\hline $2.5-3.0$ & 1,713 & $1.01(0.94-1.08)$ & 0.82 & $30.60(0.29)$ & 12 \\
\hline $3.0-3.5$ & 4,399 & 1.00 (Ref. cat.) & & & \\
\hline $3.5-4.0$ & 3,849 & $1.06(1.01-1.11)$ & 0.02 & $23.66(0.70)$ & \\
\hline$\geq 4$ & 1,572 & $1.10(1.03-1.18)$ & 0.003 & $17.41(0.94)$ & \\
\hline Trend & & $1.03(1.00-1.06)$ & 0.03 & $43.29(0.03)$ & 35 \\
\hline \multicolumn{6}{|c|}{$\begin{array}{l}\text { Adjusted for gestational age, maternal age and birth order } \\
\text { (where available) }\end{array}$} \\
\hline$<2.5$ & 528 & $0.87(0.73-1.04)$ & 0.13 & $54.62(0.001)$ & 51 \\
\hline $2.5-3.0$ & 1,643 & $0.98(0.91-1.07)$ & 0.68 & $33.76(0.17)$ & 20 \\
\hline $3.0-3.5$ & 4,212 & 1.00 (Ref. cat.) & & & \\
\hline $3.5-4.0$ & 3,697 & $1.07(1.02-1.13)$ & 0.01 & $25.92(0.58)$ & \\
\hline$\geq 4$ & 1,531 & $1.13(1.05-1.22)$ & 0.001 & $30.13(0.36)$ & 70 \\
\hline Trend & & $1.05(1.01-1.08)$ & 0.01 & $53.76(0.002)$ & 48 \\
\hline \multicolumn{6}{|c|}{ Adjusted for all available confounders as shown in Table $1^{\mathrm{c}}$} \\
\hline$<2.5$ & 517 & $0.87(0.73-1.04)$ & 0.13 & $50.60(0.004)$ & 47 \\
\hline $2.5-3.0$ & 1,600 & $0.98(0.90-1.07)$ & 0.67 & $35.37(0.13)$ & 24 \\
\hline $3.0-3.5$ & 4,127 & 1.00 (Ref. cat.) & & & \\
\hline $3.5-4.0$ & 3,617 & $1.07(1.02-1.13)$ & 0.009 & $24.24(0.67)$ & 0 \\
\hline$\geq 4$ & 1,506 & $1.11(1.03-1.20)$ & 0.01 & $32.02(0.27)$ & 13 \\
\hline Trend & & $1.04(1.01-1.08)$ & 0.01 & $53.09(0.003)$ & 47 \\
\hline \multicolumn{6}{|c|}{$\begin{array}{l}\text { Unadjusted, including only studies with a low risk of bias } \\
(\mathrm{n}=12 \text { studies })^{\mathrm{d}}\end{array}$} \\
\hline$<2.5$ & 284 & $0.92(0.75-1.11)$ & 0.37 & $18.95(0.06)$ & 42 \\
\hline $2.5-3.0$ & 906 & $1.01(0.91-1.12)$ & 0.90 & $14.96(0.18)$ & 26 \\
\hline $3.0-3.5$ & 2,286 & 1.00 (Ref. cat.) & & & \\
\hline $3.5-4.0$ & 2,057 & $1.09(1.02-1.16)$ & 0.01 & $8.86(0.63)$ & \\
\hline$\geq 4$ & 872 & $1.16(1.07-1.26)$ & 0.001 & $6.55(0.83)$ & 0 \\
\hline Trend & & $1.07(1.04-1.10)$ & $<0.001$ & $12.56(0.32)$ & 12 \\
\hline
\end{tabular}

${ }^{\mathrm{a}}$ One study [28] unavailable for the categories $<2.5 \mathrm{~kg}$ and $2.5-3.0 \mathrm{~kg}$

${ }^{\mathrm{b}}$ Adjusted for gestational age in categories $(\leq 37,38-41, \geq 42$ weeks), maternal age in categories $(<20,20-24,25-29,30-34, \geq 35$ years $)$ and birth order in categories (1st, 2nd or 3rd born) except for four studies [18, 31, 32, 43] that were not adjusted for gestational age, two studies [21, 42] not adjusted for birth order and two unadjusted studies [10, 28]

${ }^{\mathrm{c}}$ Adjusted for maternal age in categories as above, gestational age in categories (as above), birth order in categories (as above), maternal diabetes (see Table 1), Caesarean section (yes or no) and breastfeeding (see Table 1 for details)

${ }^{\mathrm{d}}$ Excluding case-control studies with controls not randomly selected or population-based or studies in which the response rate in either the case group or control group was less than $80 \%$ (or unknown) as shown in Table 1

Ref cat., reference category

\section{Discussion}

This meta-analysis demonstrates a consistent, but relatively small increase in the risk of type 1 diabetes in children who are heavier at birth. This increase in diabetes risk was more marked in studies with a low risk of bias. The association could not be explained by the confounding influence of gestational age, maternal age, birth order, Caesarean section, maternal diabetes or breastfeeding.

The main strength of this meta-analysis is that it used individual patient data (or estimates from pre-specified analyses) from 28 studies, allowing a unified approach to the investigation of birthweight and type 1 diabetes. It also included 12,058 cases, thus providing high power to 
identify associations of relatively small magnitude and allowing reliable subgroup analyses.

Although data were not available from five of the 34 studies identified, in the largest of these [30], approximate results could be extracted from a figure and were consistent with our main finding (as demonstrated by sensitivity analysis). Our search strategy was comprehensive, but it is nevertheless possible that other studies containing relevant data were not identified. Such studies, moreover, would have to be large and to have observed markedly different associations to influence our overall findings. Another potential weakness is that the birthweight association could only be adjusted uniformly for gestational age using the categories less than 38 weeks, 38 to 41 weeks and greater than 41 weeks; however, in 11 studies with available and complete gestational age information, the association with birthweight was little altered after adjustments based upon much finer categories ( $\leq 36,37-38,39,40, \geq 41$ weeks).

A previous meta-analysis of birthweight and type 1 diabetes [45] included fewer studies than ours (and based its estimate for high birthweight upon ten studies only, whereas ours was based on 29 studies). Compared with our analysis, that previous work observed a slightly more marked $17 \%$ increase in diabetes risk in children weighing over $4.0 \mathrm{~kg}$ at birth, relative to children weighing under $4.0 \mathrm{~kg}$ (prior to adjustment for confounders). Although reported for 'orientating purposes only' $[45,46]$, the less comprehensive approach of that previous study to adjustment for various confounders produced a much more marked effect of birthweight, suggesting a $43 \%$ increase in diabetes risk (based on six studies). In contrast, our analysis, using individual patient data from 29 studies with no duplicated data [47], demonstrates that confounding by various perinatal factors (such as gestational age, maternal age, birth order, Caesarean section, maternal diabetes or breastfeeding) has little influence on the birthweight association.

The mechanism behind the observed association between birthweight and type 1 diabetes remains unknown. Although our finding for birthweight remained after adjustment for various potential confounders (such as gestational age, maternal age, birth order, breastfeeding, Caesarean section delivery and maternal diabetes), it is impossible, as with all observational studies, to rule out residual confounding and it seems unlikely that birthweight plays a direct causal role. It is more probable that birthweight is a marker for some unknown exposure or exposures that influence type 1 diabetes risk such as maternal nutrition, maternal body weight or maternal diseases [5]. Ethnicity is also a possible confounder, as children born to Asian mothers, who are likely to be lighter at birth [48], also have a lower risk of type 1 diabetes [1]. It seems unlikely, however, that in these predominantly European populations this could explain the entirety of the observed association.
The observed association between type 1 diabetes and birthweight is supported by two animal studies. A recent experimental study in NOD mice demonstrated that calorific restriction during pregnancy resulted in reduced birthweight, leading to reduced risk of diabetes by 24 weeks [49]. Also an observational study in BioBreeding rats demonstrated a higher risk of diabetes with increased birthweight [50]. However, care should be taken when extrapolating animal results for aetiological factors to humans.

As fetal insulin is an important growth factor, children with greater intrauterine growth and consequently higher birthweight have pancreatic beta cells which secrete insulin more actively [51]. In vitro and other evidence shows that actively insulin-secreting beta cells are more prone to destruction via various mechanisms such as susceptibility to interleukin 1-beta and increased levels of islet antigens [52]. Further experimental animal data have been reviewed and potential mechanisms previously discussed [53]. A number of studies have found postnatal body size or growth to be associated with risk of type 1 diabetes $[54,55]$. Consequently, it is possible, and worth further investigation, that the observed association between birthweight and type 1 diabetes may somehow be mediated via postnatal growth. It is also possible that some unknown genetic factor predisposes to high birthweight and increased risk of type 1 diabetes. Although one study [56] has demonstrated that established type 1 diabetes high-risk HLA genotypes are associated with higher birthweight in the general population, another [57], which recorded established HLA and insulin gene polymorphisms, demonstrated that the observed association between type 1 diabetes and birthweight was independent of these genetic factors.

Our study suggests that the association between type 1 diabetes and birthweight is similar in children diagnosed under 5 years and in those diagnosed between 5 and 15 years of age. However, the observed association between childhood-onset type 1 diabetes and birthweight may not hold for adult-onset type 1 diabetes, as two large studies [58, 59] investigating type 1 diabetes diagnosed in young adults have shown little evidence of association with birthweight.

In conclusion, children who are heavier at birth have a significant and consistent increase in their risk of type 1 diabetes. However this increase is relatively small in magnitude and suggests that increasing trends in birthweight explain little of the rise in type 1 diabetes incidence currently being observed in many countries [3].

Acknowledgements The authors acknowledge support for the conduct of the original studies from the following: the Czech Republic Ministry of Education (grant MSM 0021620814), the Department of Health in Taiwan (grant DOH 92-TD1052), Fundacao de Amparo a Pesquisa do Estado de Sao Paulo (grant 94/0943-0), the Centro Internazionale Studi Diabete (Italy, Rome), The Swedish Child Diabetes Foundation, the NHS National Coordinating Centre for 
Research Capacity Development UK, the Research Council of Norway, the German Research Foundation (grant HE 234/1-1), the Ministry for Science and Technological Development of Serbia (number 145084, 2006-2010), EUBIROD (funded by the European Commission Health Information Strand, DG-SANCO 2005, contract number 2007115), Diabetes UK and the Northern Ireland Department of Health and Social Services. Thanks also to G. Soltész (University of Pecs, Pecs, Hungary) and G. Dahlquist (Umeå University, Umeå, Sweden), the co-ordinators of the EURODIAB Substudy 2. We also thank M. Jané (Department of Health, Barcelona, Spain).

Duality of interest The authors declare that there is no duality of interest associated with this manuscript.

\section{References}

1. International Diabetes Federation (2006) Diabetes atlas, 3rd edn. International Diabetes Federation, Belgium

2. DIAMOND Project Group (2006) Incidence and trends of childhood type 1 diabetes worldwide 1990-1999. Diabet Med 23:857-866

3. Patterson CC, Dahlquist GG, Gyurus E, Green A, Soltesz G, EURODIAB Study Group (2009) Incidence trends for childhood type 1 diabetes in Europe during 1989-2003 and predicted new cases 200520: a multicentre prospective registration study. Lancet 373:2027-2033

4. Leslie DG, Elliott RB (1994) Early environmental events as a cause of IDDM. Diabetes 43:843-850

5. Gluckman PD, Hanson MA, Cooper C, Thornburg KL (2008) Effect of in utero and early-life conditions on adult health and disease. N Engl J Med 359:61-73

6. Caughey RW, Michels KB (2008) Birth weight and childhood leukemia: a meta-analysis and review of the current evidence. Int $\mathrm{J}$ Cancer 124:2658-2670

7. Harder T, Plagemann A, Harder A (2008) Birth weight and subsequent risk of childhood primary brain tumors: a metaanalysis. Am J Epidemiol 168:366-373

8. Stene LC, Magnus P, Lie RT, Sovik O, Joner G (2001) Birth weight and childhood onset type 1 diabetes: population based cohort study. BMJ 322:889-892

9. Wei JN, Li HY, Chang CH et al (2006) Birth weight and type 1 diabetes among schoolchildren in Taiwan - a population-based case-controlled study. Diabetes Res Clin Pract 74:309-315

10. Bock T, Pedersen CR, Volund A, Pallesen CS, Buschard K (1994) Perinatal determinants among children who later develop IDDM. Diabetes Care 17:1154-1157

11. Cardwell CR, Carson DJ (2005) Patterson CC (2005) Parental age at delivery, birth order, birth weight and gestational age are associated with the risk of childhood type 1 diabetes: a UK regional retrospective cohort study. Diabet Med 22:200-206

12. Ievins R, Roberts SE, Goldacre MJ (2007) Perinatal factors associated with subsequent diabetes mellitus in the child: record linkage study. Diabet Med 24:664-670

13. McKinney PA, Parslow R, Gurney KA, Law GR, Bodansky HJ, Williams R (1999) Perinatal and neonatal determinants of childhood type 1 diabetes. A case-control study in Yorkshire, U. K. Diabetes Care 22:928-932

14. Sipetic S, Vlajinac H, Kocev N, Bjekic M, Sajic S (2005) Early infant diet and risk of type 1 diabetes mellitus in Belgrade children. Nutrition 21:474-479

15. Dahlquist G, Patterson C, Soltesz G (1999) Perinatal risk factors for childhood type 1 diabetes in Europe. The EURODIAB Substudy 2 Study Group. Diabetes Care 22:1698-1702

16. Patterson CC, Carson DJ, Hadden DR, Waugh NR, Cole SK (1994) A case-control investigation of perinatal risk factors for childhood IDDM in Northern Ireland and Scotland. Diabetes Care 17:376-381

17. Marshall AL, Chetwynd A, Morris JA et al (2004) Type 1 diabetes mellitus in childhood: a matched case control study in Lancashire and Cumbria, UK. Diabet Med 21:1035-1040

18. Polanska J, Jarosz-Chobot P (2006) Maternal age at delivery and order of birth are risk factors for type 1 diabetes mellitus in Upper Silesia, Poland. Med Sci Monit 12:173-176

19. Sadauskaite-Kuehne V, Ludvigsson J, Padaiga Z, Jasinskiene E, Samuelsson U (2004) Longer breastfeeding is an independent protective factor against development of type 1 diabetes mellitus in childhood. Diabetes Metab Res Rev 20:150-157

20. Tenconi MT, Devoti G, Comelli M et al (2007) Major childhood infectious diseases and other determinants associated with type 1 diabetes: a case-control study. Acta Diabetol 44:14-19

21. Visalli N, Sebastiani L, Adorisio E et al (2003) Environmental risk factors for type 1 diabetes in Rome and province. Arch Dis Child 88:695-698

22. Kirkwood BR, Sterne JAC (2003) Essential medical statistics, 2nd edn. Blackwell, Oxford

23. Dersimonian R, Laird N (1986) Meta-analysis in clinical-trials. Control Clin Trials 7:177-188

24. Higgins JP, Thompson SG, Deeks JJ, Altman DG (2003) Measuring inconsistency in meta-analyses. BMJ 327:557-560

25. Sterne JAC, Egger M (2001) Funnel plots for detecting bias in meta-analysis: guidelines on choice of axis. J Clin Epidemiol 54:1046-1055

26. Stukel TA, Demidenko E, Dykes J, Karagas MR (2001) Two-stage methods for the analysis of pooled data. Stat Med 20:2115-2130

27. Radon K, Windstetter D, Solfrank S, von Mutius E, Nowak D, Schwarz HP (2005) Exposure to farming environments in early life and type 1 diabetes: a case-control study. Diabetes 54:3212-3216

28. Lawlerheavner J, Cruickshanks KJ, Hay WW, Gay EC, Hamman RF (1994) Birth size and risk of insulin-dependent diabetesmellitus (IDDM). Diabetes Res Clin Pract 24:153-159

29. Soltesz G, Jeges S, Dahlquist G et al (1994) Nongenetic risk determinants for type-I (insulin-dependent) diabetes-mellitus in childhood. Acta Paediatr 83:730-735

30. Dahlquist G, Bennich SS, Kallen B (1996) Intrauterine growth pattern and risk of childhood onset insulin dependent (type I) diabetes: population based case-control study. BMJ 313:1174-1177

31. Wadsworth EJK, Shield JPH, Hunt LP, Baum JD (1997) A casecontrol study of environmental factors associated with diabetes in the under 5 s. Diabet Med 14:390-396

32. Gimeno SG, de Souza JM (1997) IDDM and milk consumption. A case-control study in Sao Paulo, Brazil. Diabetes Care 20:1256-1260

33. Bache I, Bock T, Volund A, Buschard K (1999) Previous maternal abortion, longer gestation, and younger maternal age decrease the risk of type 1 diabetes among male offspring. Diabetes Care 22:1063-1065

34. Rami B, Schneider U, Imhof A, Waldhor T, Schober E (1999) Risk factors for type I diabetes mellitus in children in Austria. Eur J Pediatr 158:362-366

35. Podar T, Onkamo P, Forsen T, Karvonen M, Tuomilehto-Wolf E, Tuomilehto J (1999) Neonatal anthropometric measurements and risk of childhood-onset type 1 diabetes. DiMe Study Group. Diabetes Care 22:2092-2094

36. Stene LC, Joner G (2004) Atopic disorders and risk of childhoodonset type 1 diabetes in individuals. Clin Exp Allergy 34:201-206

37. Sipetic SB, Vlajinac HD, Kocev NI, Marinkovic JM, Radmanovic SZ, Bjekic MD (2005) The Belgrade childhood diabetes study: a multivariate analysis of risk determinants for diabetes. Eur $\mathrm{J}$ Public Health 15:117-122

38. Svensson J, Carstensen B, Mortensen HB, Borch-Johnsen K (2005) Early childhood risk factors associated with type 1 diabetesis gender important? Eur J Epidemiol 20:429-434 
39. Malcova H, Sumnik Z, Drevinek P, Venhacova J, Lebl J, Cinek O (2006) Absence of breast-feeding is associated with the risk of type 1 diabetes: a case-control study in a population with rapidly increasing incidence. Eur J Pediatr 165:114-119

40. Hathout EH, Beeson WL, Ischander M, Rao R, Mace JW (2006) Air pollution and type 1 diabetes in children. Pediatr Diabetes 7:81-87

41. Haynes A, Bower C, Bulsara MK, Finn J, Jones TW, Davis EA (2007) Perinatal risk factors for childhood type 1 diabetes in Western Australia - a population-based study (1980-2002). Diabet Med 24:564-570

42. Borras Perez MV, Freitas A, Jane M, Gispert R, Castell C (2007) Association between type 1 diabetes and perinatal factorsCatalonia study. Pediatr Diabetes 8(Suppl 7):67, Abstract

43. Rosenbauer J, Herzig P, Giani G (2008) Early infant feeding and risk of type 1 diabetes mellitus - a nationwide population-based case-control study in pre-school children. Diabetes Metab Res Rev 24:211-222

44. Waldhoer T, Rami B, Schober E (2008) Perinatal risk factors for early childhood onset type 1 diabetes in Austria - a populationbased study (1989-2005). Pediatr Diabetes 9:178-181

45. Harder T, Roepke K, Diller N, Stechling Y, Dudenhausen JW, Plagemann A (2009) Birth weight, early weight gain, and subsequent risk of type 1 diabetes: systematic review and metaanalysis. Am J Epidemiol 169:1428-1436

46. Harder T, Plagemann A (2009) Two authors reply. Am J Epidemiol 170:530-531

47. Cardwell CR, Patterson CC (2009) Re "Birth weight, early weight gain, and subsequent risk of type 1 diabetes: systematic review and meta-analysis". Am J Epidemiol 170:529-530

48. Office for National Statistics (2008) Birthweight and gestational age by ethnic group, England and Wales 2005: introducing new data on births. Health Stat Q 39:22-31
49. Oge A, Isganaitis E, Jimenez-Chillaron J et al (2007) In utero undernutrition reduces diabetes incidence in non-obese diabetic mice. Diabetologia 50:1099-1108

50. Pedersen CR, Bock T, Hansen SV, Hansen MW, Buschard K (1994) High juvenile body weight and low insulin levels as markers preceding early diabetes in the BB rat. Autoimmunity 17:261-269

51. Hill DE (1980) Fetal endocrine pancreas. Clin Obstet Gynecol 23:837-847

52. Brown RJ, Rother KI (2008) Effects of beta-cell rest on beta-cell function: a review of clinical and preclinical data. Pediatr Diabetes 9:14-22

53. Dorner G, Plagemann A (1994) Perinatal hyperinsulinism as possible predisposing factor for diabetes mellitus, obesity and enhanced cardiovascular risk in later life. Horm Metab Res 26:213-221

54. Hypponen E, Virtanen SM, Kenward MG, Knip M, Akerblom HK (2000) Obesity, increased linear growth, and risk of type 1 diabetes in children. Diabetes Care 23:1755-1760

55. The EURODIAB Substudy 2 Study Group (2002) Rapid early growth is associated with increased risk of childhood type 1 diabetes in various European populations. Diabetes Care 25:1755-1760

56. Larsson HE, Lynch K, Lernmark B et al (2005) Diabetesassociated HLA genotypes affect birthweight in the general population. Diabetologia 48:1484-1491

57. Stene LC, Thorsby PM, Berg JP, Ronningen KS, Undlien DE, Joner $\mathrm{G}$ (2006) The relation between size at birth and risk of type 1 diabetes is not influenced by adjustment for the insulin gene $(-23 \mathrm{HphI})$ polymorphism or HLA-DQ genotype. Diabetologia 49:2068-2073

58. Dahlquist GG, Pundziute-Lycka A, Nystrom L (2005) Birthweight and risk of type 1 diabetes in children and young adults: a population-based register study. Diabetologia 48:1114-1117

59. Lammi N, Blomstedt PA, Moltchanova E, Eriksson JG, Tuomilehto J, Karvonen M (2009) Perinatal risk factors in young adult-onset type 1 and type 2 diabetes a population-based case-control study. Acta Obstet Gynecol Scand 88:468-474 